\title{
Associativismo e Participação Popular O trabalho de organização popular pelas assessorias jurídicas universitárias
}

\author{
Associative Practice and Popular Participation \\ The work of popular organization by university legal assistance
}

Orlando Vignoli Neto

Graduando em Direito pela UFMG

orlandovignoli@gmail.com

\begin{abstract}
Resumo: Este trabalho pretende analisar a importância da participação das assessorias jurídicas universitárias em trabalhos de organização popular tendo como principal ferramenta política as associações comunitárias. A partir do estudo do método de extensão popular desenvolvido pelas assessorias jurídicas, nota-se que a organização popular é pressuposto para o processo transformação da realidade concreta que o método se propõe a desenvolver. Assim, partindo da diferença entre organizações populares e do "terceiro setor", o artigo pretende concluir como a prática associativista é importante na atuação das assessorias.
\end{abstract}

Palavras-chave: Associação comunitária. Associativismo. Organização popular. Educação popular. Assessoria jurídica universitária.

\begin{abstract}
This paper discusses the importance of the work of university legal assistance in works of popular organization whose main policy tool community associations. From the study of the method of popular extension developed by the legal assistance, we note that the popular organization is presupposed in the process of reality changing that the method proposes to develop. Thus, based on the difference between popular organizations and the "third sector", the article intends to complete that associative practice is important in the performance of the legal assistance.
\end{abstract}

Keywords: Community association. Associative practice. Popular organization. Popular education. University legal assistance.

Originais recebidos em: 23/03/2014

Aceito para publicação em: 27/06/2014

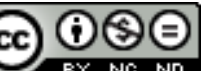

Comercial-Vedada a criação de obras derivadas 3.0 Unported License. 


\section{Assessoria Jurídica Universitária Popular (AJUP) e Organização Popular}

As assessorias jurídicas universitárias são coletivos de estudantes universitários, notadamente das Faculdades de Direito, que desenvolvem projetos de assessoria jurídica popular por meio da extensão universitária.

De acordo com Ribas (2012, p. 355), a assessoria jurídica popular:

[...] consiste no trabalho desenvolvido por advogados populares, estudantes, educadores, militantes dos direitos humanos em geral, entre outros; de assistência, orientação jurídica e/ou educação popular com movimentos sociais, com o objetivo de viabilizar um diálogo sobre os principais problemas enfrentados pelo povo na busca pela realização de direitos fundamentais para uma vida com dignidade, seja por meio dos mecanismos oficiais, institucionais, jurídicos, extrajurídicos, políticos, seja por meio da conscientização.

Quando desenvolvida no meio estudantil, a assessoria jurídica popular assume contornos peculiares, que dizem respeito à própria disputa do estudo do direito nas universidades. Percebe-se, assim, que há nas assessorias estudantis uma ênfase nas atividades educativas, no protagonismo dos estudantes na organização de seus trabalhos e na autonomia desses grupos em relação à própria universidade e outras instituições (RIBAS, 2012, p. 355-356). Por isso, de acordo com essas características, não se deve afirmar categoricamente que essas atividades sempre se desenvolvem de maneira institucionalizada como projetos ou $\operatorname{programas}^{1}$ de extensão universitária. Mas, certamente, pode-se dizer que são universitárias. Não apenas pelo fato de serem atividades protagonizadas por estudantes universitários, mas em decorrência da disputa de um projeto de universidade, em direção à universidade popular. A universidade popular aqui é concebida não com o conceito pejorativo do termo, que designa as instituições de ensino voltadas a pessoas com limitada condição de acesso às outras universidades $^{2}$ (universidade precarizada), e tampouco o projeto de Universidade Popular dos Movimentos Sociais (UPMS) proposto por SANTOS (2003, p. 4), como um espaço permanente de diálogo entre movimentos sociais e demais organizações sociais. A disputa por uma universidade popular compreende a apropriação radical da universidade pelo povo, para que o conhecimento ali seja produzido pelo povo e para o povo.

\footnotetext{
${ }^{1}$ Programa é um conjunto articulado de projetos e de outras ações de extensão.

${ }^{2}$ Exemplo desse tipo de universidade popular é a John C. Campbell Folk School nos Estados Unidos

Em Debat: Rev. Dig., ISSNe 1980-3532, Florianópolis, n. 10, p. 4-18, jul-dez, 2013.
} 
As assessorias jurídicas universitárias fazem essa disputa por meio da extensão universitária. A extensão universitária tradicional, desenvolvida, sobretudo, a partir dos anos sessenta, se frustrou, não obstante os seus objetivos genuínos (FURMANN, 2003, p. 45). Apesar de originalmente pensarem a extensão como o cumprimento da responsabilidade social da universidade, levando o conhecimento nelas produzidos para a sociedade, a extensão universitária é desenvolvida inicialmente pautada em marcos teóricos assistencialistas e tecnicistas. De maneira quase messiânica pretendia-se levar às comunidades carentes um conhecimento já pronto, tratando-os como verdadeiro objeto do estudo científico, objetivando o mero aperfeiçoamento técnico dos estudantes.

Ao tratarmos da extensão universitária no âmbito das Faculdades de Direito, a extensão tradicionalmente trabalhada se insere nos marcos dos chamados serviços legais tradicionais. Os principais serviços legais tradicionais desenvolvidos nos cursos de direito estão no âmbito da chamada assistência judiciária, que consiste na prestação gratuita de serviços advocatícios a pessoas economicamente hipossuficientes, por meio dos escritórios-modelos ou núcleos de prática jurídica (FURMANN, 2003, p. 50). Esses serviços legais tradicionais são marcados por essa concepção assistencialista da extensão tradicional, pois a partir do conhecimento jurídico produzido dentro da universidade os estudantes meramente captam as demandas externas para processá-las no contencioso jurídico e entregam o problema em questão já solucionado, tratando os assistidos como o objeto do estudo. Segundo a classificação do professor Celso Campilongo presente na obra de Furmann (2003, p. 60), os serviços legais tradicionais tem como características o individual, o paternalismo, a apatia, o mistério, o legal, o controle de litigiosidade, o técnico jurídico, as demandas clássicas, a ética utilitária, e a certeza jurídica.

Por outro lado, os trabalhos desenvolvidos pelas assessorias jurídicas universitárias se inserem em outro marco teórico de extensão. A chamada extensão popular, que tem como principal teórico Paulo Freire, não é simples troca de saberes, mas produção conjunta do conhecimento. Por ser a atividade de extensão educativa por excelência, que tem por objetivo articular o ensino e a pesquisa de maneira indissociável, viabilizando a relação transformadora entre a universidade e a sociedade ${ }^{3}$, os projetos de extensão popular valem-se do referencial teórico da educação popular. Nos marcos da educação popular, a sociedade não é mero objeto de estudo ou simples

\footnotetext{
${ }^{3}$ Conceito de extensão delineado pelo Fórum Nacional de Pró-Reitores de Extensão de Universidades Públicas Brasileiras.
}

Em Debat: Rev. Dig., ISSNe 1980-3532, Florianópolis, n. 10, p. 4-18, jul-dez, 2013. 
público alvo para a reprodução do conhecimento anteriormente concebido nos muros da universidade. Assumido a dimensão popular, a extensão transpõe os muros institucionais, adquirindo, como trabalho social, a dimensão de exterioridade, abarcando ações educativas em parceria com movimentos sociais e outros instrumentos organizativos da sociedade civil. É um trabalho que coloca o povo como sujeito da produção do conhecimento em conjunto com os estudantes universitários. Além disso, por óbvio, a extensão popular trabalha com os sujeitos ditos "populares" da sociedade civil. De acordo com RIBAS (2012, p. 373):

Entende-se que "popular" se refere a povo, que é uma categoria que se modifica com a história, como todas as categorias que representam um conteúdo real. Para Marx, o povo, essa conceituação rigorosa e útil, está constituído por aqueles setores da sociedade que sofrem dominação e exploração. A exploração refere-se ao campo da produção e a dominação, ao da ideologia.

No âmbito do direito, esse modelo inovador de extensão se faz por meio das assessorias jurídicas universitárias. Apesar de "assessoria" ser correntemente utilizada como sinônimo de "assistência", a assessoria foi a palavra utilizada para simbolizar essa nova metodologia de extensão. De acordo com Furmann (2003, p. 63), “a postura política da Assessoria, por surgir no espaço discursivo dos movimentos populares, é uma postura de contestação e não de caridade". É uma maneira de associar o direito aprendido na universidade, dos códigos, dos tribunais e da doutrina com o direito vivenciado na realidade do povo. E a partir desse diálogo é produzido um novo conhecimento a respeito do objeto de estudo, que é o direito. Se no modelo tradicional de extensão o objeto de estudo é a comunidade, ou o seu comportamento frente a aplicação do direito, na extensão popular o objeto é o próprio direito e suas formas. Assim, ainda de acordo com a classificação de Campilongo, que insere a assessoria jurídica como serviços legais inovadores, as assessorias jurídicas universitárias tem por características o coletivo, a organização, a participação, o desencantamento, o extralegal, a explosão de litígios, o multiprofissionalismo, as demandas de impacto social, a ética comunitária e a justiça.

O presente estudo tem por objetivo estudar as três primeiras características dos serviços legais inovadores, portanto, o coletivo, a organização e a participação. Assim, pretende-se demonstrar por meio do estudo da teoria da ação dialógica o papel central que as AJUP's desenvolvem no processo de organização popular e como as associações podem ser um instrumento político tático para esse objetivo. 


\section{Teoria da ação dialógica}

De acordo com o que já foi exposto, percebe-se que as assessorias jurídicas universitárias trabalham necessariamente com dois eixos de atuação principais: a assessoria jurídica popular e a educação popular em direitos humanos. Em decorrência de seu caráter estudantil, a educação popular em direitos humanos assume nas assessorias universitárias um caráter transversal, que deve estar presente em todas as atividades do projeto para que se faça extensão popular. Até mesmo a assessoria jurídica, nos marcos da extensão popular, vale-se de um processo pedagógico para ambos os sujeitos, assessores e assessorados. Assim, o início do trabalho de assessoria deve sempre começar de maneira pedagógica desde o diagnóstico como durante toda a atuação, de acordo com o que Paulo Freire chama de teoria da ação dialógica.

A teoria da ação dialógica, em oposição à teoria da ação antidialógica, consiste no método de educação popular, pautado na comunicação, no diálogo, na construção compartilhada do conhecimento. Como ressalta FREIRE (1987, p. 19), "solidarizar-se com os oprimidos, que é mais que prestar assistência a trinta ou a cem, mantendo-os atados, contudo, à mesma posição de dependência. A solidariedade, exigindo de quem se solidariza, que "assuma" a situação com quem se solidarizou, é uma atitude radical". Assim, tem como características a colaboração, a união, a organização e a síntese cultural.

A grande tarefa dos oprimidos reside na possibilidade de libertar a si e aos opressores. Entretanto, os oprimidos, enquanto "hospedeiros" do próprio opressor, somente na medida em que se descobrirem enquanto "hospedeiros" do opressor é que poderão contribuir para o nascimento de sua práxis libertadora (FREIRE, 1987, p. 17). Posteriormente a esse momento de descoberta da condição de hospedeiro da opressão, há um processo de inserção crítica do oprimido na realidade, desvelando o mundo da opressão e suas contradições. Ele percebe que apenas ele tem essa condição de libertação, e naturalmente teme essa opção, pois essa superação não pode se dar de forma idealista, e se faz indispensável aos oprimidos a luta por sua libertação. E essa luta pela libertação só se dá na práxis, que é reflexão e ação dos homens sobre o mundo para transformá-lo (FREIRE, 1987, p. 21).

Dessa forma, descobrindo nitidamente o opressor, os oprimidos se engajam na luta organizada por sua libertação (FREIRE, 1987, p. 29). E não podemos nos esquecer 
de que a libertação dos oprimidos é a libertação de homens e não de "coisas". Por isso, se não é autolibertação, ninguém se liberta sozinho e ninguém liberta ninguém, os homens se libertam em comunhão.

Portanto, percebe-se que a educação popular enquanto referencial teórico da extensão popular é muito mais do que simples educação das massas para que conheçam os seus direitos. É também educação para o exercício político da cidadania, que tem como pressuposto tático a organização popular para o alcance da estratégia, que é a transformação concreta da realidade.

\section{Teoria da Organização Política}

A partir da aplicação da teoria da ação dialógica conclui-se que é necessário que o povo esteja organizado para dar ensejo ao processo de transformação da realidade. Decerto, essa transformação constitui-se de um longo processo que possui várias etapas, objetivos e obstáculos. Para superar cada uma delas, as organizações políticas atuam de maneira diferente, adotando para cada situação determinada tática política. Marta Harnecker (1985, p. 46) define a tática política como las distintas operaciones o medidas concretas que se adoptan para llevar a cabo el plan estratégico. O plano estratégico, por sua vez, é uma visão ampla de todas as forças para atingir o objetivo fixado, no caso, a transformação da realidade.

Dessa forma, se para atingir determinado objetivo estratégico deve-se adotar diferentes táticas de acordo com determinada leitura que se faz da realidade concreta, conclui-se que o caráter da organização popular assume diferentes formatos de acordo com o objetivo que se quer alcançar. Lênin deixa isso claro em "O quê fazer" e entende que a ferramenta necessária para conduzir o processo revolucionário é o partido político.

Do mesmo modo (e como consequência) a organização de um partido socialdemocrata revolucionário deve necessariamente constituir um gênero diferente da organização dos operários para a luta econômica. A organização dos operários deve ser, em primeiro lugar, profissional; em segundo lugar, a maior possível; em terceiro lugar, a menos clandestina possível [...]. Ao contrário, a organização dos revolucionários deve englobar, antes de tudo e principalmente, homens cuja profissão é a ação revolucionária [...]. (LENIN, 1902, p. 60)

Apesar de não ser possível dividir temporal e espacialmente o processo de transformação social, pode-se dizer que o partido é a ferramenta necessária para 
desencadear a ruptura com a atual realidade. Entretanto, como foi analisado da teoria da ação dialógica, dessa ruptura revolucionária é preciso que o oprimido se descubra enquanto hospedeiro do opressor e se insira criticamente na realidade. E o partido político não é o espaço adequado para isso, pois, como destaca Lênin, o partido é um espaço de pessoas cuja profissão é a ação revolucionária. Portanto, os demais processos que devem ser abrangentes.

Assim, as AJUP's podem trabalhar com os diversos tipos de organização popular bem como fomentá-las. Em se tratando de assessorias de caráter eminentemente pedagógicas, trabalharão preferencialmente com as organizações de luta econômica. Por isso elas têm como principais parceiros os movimentos sociais, os sindicatos, os centros e diretórios acadêmicos, os conselhos populares, algumas ONGs, e as associações de moradores.

Principalmente após a Constituição de 1988 e as elaborações em torno do Estado Democrático de Direito, há uma ênfase nas organizações da sociedade civil, que passam a dispor de uma série de prerrogativas legais e até mesmo constitucionais. Elas podem propor ações coletivas, coordenar determinadas políticas públicas e desenvolver trabalhos de assistência social. Entretanto, essa ideia que ganhou força no Brasil principalmente a partir da década de 1990 de que a sociedade civil autônoma deve substituir o Estado nas suas atribuições fundamentais, e que o chamado "terceiro setor" é uma das alternativas à crise contemporânea, pode confundir as assessorias jurídicas universitárias de quais são verdadeiramente organizações de caráter popular.

\section{Terceiro setor e questão social}

O conceito em torno do que efetivamente representa o "terceiro setor", tanto no que diz respeito às organizações que o compõe, quanto no que diz respeito ao seu papel de organização social é conflituoso. O conceito hegemônico do termo é desenvolvido nos Estados Unidos, sendo a tradução de "third sector", construído a partir de um recorte do social em esferas. O Estado seria o "primeiro setor", sendo este uma pessoa jurídica de direito público que tem finalidades públicas; o mercado seria o "segundo setor", composto por pessoas jurídicas de direito privado para executar finalidades também privadas; e por último a "sociedade civil" comporia o "terceiro setor", que se constitui por pessoas jurídicas de direito privado que tem por objetivo finalidades de 
utilidade e interesse público. Segundo esse conceito hegemônico, fazem parte do terceiro setor Organizações Não-Governamentais (ONGs), entidades filantrópicas, fundações, Organizações Sociais (OS’s), Organizações da Sociedade Civil de Interesse Público (OSCIP's) e demais organizações e associações de interesse público sem fins lucrativos. Portanto, politicamente, o "terceiro setor" representaria a "sociedade civil" coordenando de forma auto-organizada as políticas de interesse público, atuando de maneira filantrópica, em decorrência da ineficiência da atividade burocrática do Estado.

Assim, o "terceiro setor" emprega o conceito de "sociedade civil" que se consolidou e ganhou legitimidade nos anos do regime militar para conceituar as iniciativas de resistência face ao autoritarismo do Estado. Entretanto, é preciso uma abordagem sobre o "terceiro setor" não como um fenômeno isolado, mas que tem como ponto de partida o movimento e as tendências das transformações do capital como o todo (MONTAÑO, 2010, p. 52). Ainda sobre o conceito de "sociedade civil", Virgínia Fontes esclarece em sua obra O Brasil e o capital-imperialismo:

Esta passou a ser interpretada sobretudo como o terreno dos movimentos populares, olvidando-se do peso histórico e social das organizações de base empresarial e ficando à sombra o empresariamento que se iniciava no interior das ONGs. [...] As entidades empresariais atuavam corporativa e politicamente como sociedade civil, no sentido gramsciano, como aparelhos privados de hegemonia, e participavam intimamente do Estado, antes e durante o período ditatorial. Apresentavam-se, entretanto, como sociedade no sentido liberal, contrapondo-se ao Estado. (FONTES, 2010, p. 240)

A ideia de "terceiro setor" apropria-se de antigas bandeiras da esquerda principalmente nos contextos autocráticos, ditatoriais, onde o Estado é totalmente cooptado pelo poder político. Portanto, quando a sociedade civil torna-se o espaço privilegiado de organização, mobilização e demanda/resposta da população, é capciosamente distorcida para a compreensão da desnecessidade da tomada do Estado como objetivo estratégico (MONTAÑA, 2010, p. 153).

Dessa forma, o chamado "terceiro setor" na verdade representa uma denominação propositalmente equivocada para designar um fenômeno real de implementação de políticas neoliberais. Em lugar das organizações do Estado, supostamente burocrático e ineficiente, ou do mercado, as organizações da sociedade civil assumem a tarefa de responder às demandas sociais. Ainda de acordo com Montaña (2010, p. 185):

O fenômeno em questão não é, portanto, o desenvolvimento de organizações de um "setor" em detrimento da crise de outro, mas a alteração de um padrão de resposta social à "questão social" (típica do Welfare State), com a desresponsabilização do Estado, a desoneração do capital e a auto- 
responsabilização do cidadão e da comunidade local para esta função (típica do modelo neoliberal ou funcional a ele).

Portanto, a ideia de "terceiro setor" não deve ser empregada como um conceito categórico que designa determinadas organizações da sociedade civil que desempenham atividades de relevante interesse público. O "terceiro setor" tem um recorte histórico que no Brasil está intimamente relacionado com a ascensão do neoliberalismo na década de 1990, concretizado a partir do Plano Diretor de Reforma do Aparelho do Estado elaborado pelo Ministério da Administração e Reforma do Estado (MARE), coordenado por Bresser Pereira em 1995. A partir desse programa, são aprovadas diversas emendas constitucionais, leis complementares e leis ordinárias ${ }^{4}$ que tinham por objetivo a flexibilização dos serviços públicos e a privatização de atividades econômicas exploradas pelo Estado.

Não é por acaso que, considerando o "terceiro setor" como uma esfera nãoestatal ("primeiro setor") e não-mercantil ("segundo setor"), mas identificado com a "sociedade civil", na maioria das análises das organizações que compõe esse setor estejam ausentes organizações sindicais, movimentos sociais e associações comunitárias combativas. Mais do que um conceito rígido e neutro, o "terceiro setor" denomina um movimento político típico do neoliberalismo.

\section{Associativismo e participação popular}

Tecidas as críticas ao movimento denominado "terceiro setor", faz-se necessário traçar um paralelo com as formas de organização popular. As organizações populares, portanto, estão mais relacionadas com o seu conteúdo - ou seja, com os objetivos pretendidos pela organização - do que propriamente com a sua forma. E como já foi delineado nesse trabalho, existe várias formas de se organizar de acordo com determinados objetivos estratégicos. E sendo primordial que as assessorias jurídicas universitárias trabalhem com processo pedagógico que privilegie o reconhecimento dos oprimidos enquanto "hospedeiros" do opressor e a sua inserção crítica na realidade, existem várias formas organizativas possíveis para cumprir essa tarefa. Contudo, uma

\footnotetext{
${ }^{4}$ Como exemplo podemos citar a Lei ${ }^{\circ}{ }^{8.031 / 90}$ que institiu o Programa Nacional de Desestatização; a Lei $n^{\circ}$ 9.637/98 que dispõe sobre a qualificação de entidades como organizações sociais, criou o Programa Nacional de Publicização e extinguiu órgãos e entidades, absorvendo suas atividades por organizações sociais; e a Lei $n^{\circ}$ 9.790/99 que instituiu as Organizações Sociais de Interesse Público (OSCIP's).
} 
organização que vem ganhando relevância política e legislativa no Estado Democrático de Direito é a associação comunitária.

Historicamente as associações representam uma forma de organização recorrente da classe trabalhadora no âmbito jurídico. O conceito jurídico usual de associação a identifica como uma pessoa jurídica de direito privado sem fins lucrativos, criada a partir da organização de duas ou mais pessoas, unidas em torno de um objetivo comum. A Declaração Universal dos Direitos Humanos de 1948 já estipulava em seu art. 20 que "toda a pessoa tem direito à liberdade de reunião e de associação pacíficas". Já na Constituição da República Federativa do Brasil em seu art. 5, XVII é disposto que "é plena a liberdade de associação para fins lícitos, vedada a de caráter paramilitar”, bem como no inciso XVIII que diz que a "criação de associações e, na forma da lei, a de cooperativas independem de autorização, sendo vedada a interferência estatal em seu funcionamento". Assim, percebemos na história o exercício por parte da classe trabalhadora do direito que conquistou de se associar livremente. Como exemplo, temos os sindicatos, que são associações de caráter sindical, bem como os partidos políticos, que são associações de caráter partidário. Na história, temos também o exemplo da Associação Internacional dos Trabalhadores (AIT), conhecida também como Primeira Internacional. A Primeira Internacional foi uma associação, com um conjunto de regras que formavam um estatuto, que tinha por objetivo unir uma variedade de grupos políticos de esquerda na luta pelo progresso e pela emancipação dos trabalhadores. Atualmente as formas associativas estão cada vez mais diversificadas e representam um espaço da luta dos oprimidos contra o atual sistema opressor. Por isso, se organizam por diversos grupos, como os trabalhadores das diversas categorias, os estudantes, os camponeses, os quilombolas, os indígenas, e as associações de bairro ou associações comunitárias.

As associações comunitárias ou de bairro têm como objetivo organizar e centralizar forças de moradores de uma determinada comunidade para representar, de maneira mais eficaz, interesses comuns. A criação de associações de bairro é motivada pela necessidade de conquistar melhores condições de infraestrutura, transporte, segurança, lazer, educação, entre outros setores, a ausência de representatividade dos marginalizados nos espaços de decisão. Possui muitas vezes um recorte de classe, pois, quando organizadas em comunidades periféricas, abrangem um grande número de trabalhadores de diversas categorias, mulheres, jovens e marginalizados em geral. 
A associação comunitária é uma organização tática não somente em razão da possibilidade desse recorte, mas também enquanto instrumento pedagógico para a práxis revolucionária, exercitando a organização popular. Por meio dela, e da estrutura flexível de atuação que proporciona, é possível construir um modelo democrático de organização mais próxima dos movimentos sociais, com o bônus da legitimidade jurídica que ela detém. Esse vínculo institucional, ao mesmo tempo em que não é engessado, permite que esses associados exerçam a participação popular por meio dos mecanismos institucionais de democracia direta. Será possível, assim, a participação organizada em conselhos, audiências públicas, orçamento participativo e a eventual propositura de ações coletivas.

Não é por acaso que a legislação vem conferindo às associações diversas prerrogativas legais, principalmente no que diz respeito à participação popular nas cidades, em decorrência de conflitos multitudinários característicos da organização caótica dos grandes centros urbanos. Como exemplo, temos a possibilidade de serem as associações legitimadas ativas em ação civil pública ${ }^{5}$, e como substituto processual para a propositura de ação de usucapião especial urbana ${ }^{6}$. Também participam na gestão democrática da cidade por meio de associações representativas dos vários segmentos da comunidade na formulação, execução e acompanhamento de planos, programas e projetos de desenvolvimento urbano $^{7}$ e do processo de elaboração do Plano Diretor das cidades com mais de 200 mil habitantes ${ }^{8}$.

É fundamental que a parte consciente da classe trabalhadora compreenda a necessidade da conciliação da disputa por meios institucionais e não institucionais (LÊNIN, 1920, p. 6). A disputa de consciência para uma ruptura revolucionária deve ser feita nos instrumentos em que as massas têm referência, legitimidade essa que determinadas associações vem conquistando no atual momento histórico. É possível também organizar determinado grupo não mais apenas em relação à categoria, como nos sindicatos, nem apenas à determinada reivindicação, como nos movimentos sociais. Surge a possibilidade de fazer um recorte mais amplo de categorias e reivindicações, abrangendo pessoas que não tem referência nas demais entidades.

Além disso, enquanto pessoa jurídica, a formação de uma associação necessita de amparo técnico. Assim, deve-se ressaltar a importância das assessorias jurídicas

\footnotetext{
${ }^{5}$ Art. $5^{\circ}$, V da Lei $\mathrm{n}^{\circ} 7.347$ de 24 de Julho de 1985.

${ }^{6}$ Art. 12, III da Lei ${ }^{\circ} 10.257$ de 10 de Julho de 2001.

${ }^{7}$ Art. $2^{\circ}$, II da Lei $\mathrm{n}^{\mathrm{o}} 10.257$ de 10 de Julho de 2001.

${ }^{8}$ Art. $40, \S 4^{\circ}$, I da Lei n ${ }^{\circ} 10.257$ de 10 de Julho de 2001.
}

Em Debat: Rev. Dig., ISSNe 1980-3532, Florianópolis, n. 10, p. 4-18, jul-dez, 2013. 
universitárias nesse processo, que devem ter o associativismo como horizonte de sua atuação, coerente com o marco teórico da extensão popular que se propõe a desenvolver. Por meio do acompanhamento das AJUP's, a comunidade terá uma assessoria jurídica pautada na educação popular em direitos humanos, a partir de uma construção emancipatória, que permita a comunidade se auto-organizar desde sua criação e registro até o seu funcionamento. E o acompanhamento, na perspectiva da assessoria, vai além da simples elaboração do estatuto e do seu respectivo registro. Envolve todo um acompanhamento político-pedagógico para que a associação funcione verdadeiramente conforme as diretrizes coletivamente acordadas.

A associação é identificada como verdadeiro tema-gerador (FREIRE, 1987, p. 50) em várias comunidades. A temática mobiliza essas pessoas e dialoga com a sua realidade concreta, a partir do momento em que elas se mobilizam a partir da vivência que elas têm em seu cotidiano. Como exemplo, temos a experiência da Assessoria Jurídica Universitária Popular da Universidade Federal de Minas Gerais (AJUPUFMG), que trabalha em parceria com os moradores da comunidade Pedreira Prado Lopes, em Belo Horizonte - MG. O início dos trabalhos da AJUP-UFMG na Pedreira em 2012 teve como grande fator de mobilização durante o período de um ano a reativação da associação de moradores. Após várias tentativas de mobilização popular em torno da pauta, os moradores não conseguiram reativar a antiga associação, que estava cooptada pelo poder público e irregular há muitos anos, sem convocar eleições e sem realizar qualquer outra atividade. Em razão disso, moradores da comunidade decidiram criar uma nova associação que resgatasse o movimento comunitário na favela. A partir dessa ideia, a AJUP-UFMG iniciou um longo processo de elaboração do estatuto da nova associação junto com os moradores. Foram feitas diversas reuniões em que foram debatidos os objetivos da associação, o seu funcionamento, eleições, entre outros dispositivos. Após a elaboração do estatuto, foi convocada uma eleição na comunidade para decidir se queriam uma nova associação, que contou com o voto de mais de 500 moradores. Em 2014, a nova associação dos moradores da Pedreira Prado Lopes está pronta para ser registrada é acompanhada pela assessoria.

\section{Considerações finais}


Portanto, pode-se referir à expressão "associativismo" como a prática social da criação e gestão das associações e como a defesa dessa prática de associação enquanto processo de organização popular para alcançar determinados objetivos estratégicos. Ao designar forma de organização social, o associativismo expressa a organização espontânea de um grupo de pessoas em um instrumento da satisfação de suas necessidades coletivas em vista determinados objetivos, seja por meio de partidos políticos, sindicatos, movimentos sociais ou associações comunitárias. Enquanto defesa da prática associativa, expressa os esforços depreendidos por determinado grupo para colaborar na construção dessas organizações.

Por isso, as assessorias jurídicas universitárias possuem caráter associativista, pois faz parte de seu método de atuação a organização popular. A assessoria tem um caráter eminentemente coletivo, de maneira que os seus trabalhos sociais nunca se darão na esfera individual, mas sempre tendo em vista o coletivo, por isso a atuação em parceria com organizações de caráter coletivo. Dessa forma, as AJUP's fomentam a inserção crítica do povo na realidade, incentivando a participação popular nos espaços de disputa do poder.

Por fim, é necessário ressaltar que a associação não é uma organização que tem por finalidade superar as demais formar de organização, como os partidos políticos, sindicatos ou movimentos sociais. Elas cumprem um papel diferente na atual conjuntura revolucionária, suprindo demandas que não são alcançadas por outras organizações. $\mathrm{Na}$ realidade, é preciso que haja uma relação de cooperação e até mesmo de disputa ideológica de seus rumos por esses grupos. Dessa forma, vê-se a associação como instrumento fundamental para a consolidação da participação popular organizada e para a promoção da dignidade humana, a partir do momento que se une os oprimidos em vista a sua libertação de maneira autônoma.

\section{Referências}

BRASIL. Constituição da República Federativa do Brasil de 1988. Diário Oficial [da República Federativa do Brasil], Brasília, 05 outubro de 1988.

. Estatuto da Cidade. Diário Oficial [da República Federativa do Brasil], Brasília, 11 de julho de 2001. 
FONTES, Virgínia. O Brasil e o capital-imperialismo: Teoria e história. $2^{\mathrm{a}}$ ed. Rio de Janeiro: Editora UFRJ, 2010.

FREIRE, Paulo. Pedagogia do Oprimido. $17^{\mathrm{a}}$ ed. Rio de Janeiro: Paz e Terra, 1987. . Extensão ou Comunicação?. $7^{\mathrm{a}}$ ed. Rio de Janeiro: Paz e Terra, 1983.

FURMANN, Ivan. Assessoria Jurídica universitária popular: da utopia estudantil à ação política. Monografia de graduação em Direito. Universidade Federal da Paraná. Paraná, 2003.

HARNECKER, Marta. Estrategia y Tática. Disponível em:

$<$ http://www.consultapopular.org.br/sites/default/files/Estrat $\% \mathrm{C} 3 \% \mathrm{~A} 9 \mathrm{gia} \% 20 \mathrm{e} \% 20 \mathrm{t} \% \mathrm{C}$ 3\%A1tica.pdf $>$. Acesso em março de 2014. Publicado em 1985.

LENIN, Vladimir Ilytch. Esquerdismo: doença infantil do comunismo. Disponível em: $<$ http://www.consultapopular.org.br/sites/default/files/esquerdismo-1.pdf $>$. Acesso em março de 2014. Publicado em 1920.

LENIN, Vladimir Ilytch. Que fazer? Problemas candentes do nosso movimento.

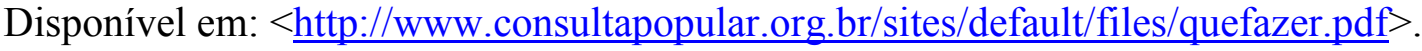
Acesso em março de 2014. Publicado em 1902.

MELO NETO, José Francisco de. Extensão Universitária - diálogos populares. Disponível em:

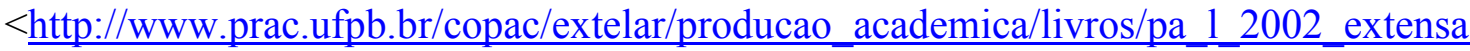
o dialogos populares.pdf $>$. Acesso em março de 2014.

Extensão Popular. Disponível em:

$<$ http://www.prac.ufpb.br/copac/extelar/producao_academica/ensaios/pa_e_extensao_p opular 2005.pdf> Acesso em março de 2014.

MONTAÑO, Carlos. Terceiro Setor e Questão Social: Crítica ao padrão emergente de intervenção social. $6^{\text {a }}$ ed. São Paulo: Cortez, 2010.

RIBAS, Luiz Otávio. A assessoria estudantil com movimentos sociais brasileiros nas décadas de 1960 a 2000. In: LIMA, Gretha Leite Maia Correia; TEIXEIRA, Zaneir Gonçalves (Org.) Ensino jurídico: os desafios da compreensão do direito. Fortaleza: Faculdade Christus, 2012, p. 355-376. 
- Assessoria jurídica popular universitária e direitos humanos: o diálogo emancipatório entre estudantes e movimentos sociais (1988-2008). Disponível em: $<$ http://www.ccj.ufsc.br/capturacriptica/documents/n1v1/parciais/ribas2.pdf $>$. Acesso em março de 2014.

SANTOS, Boaventura de Sousa. A Universidade Popular dos Movimentos Sociais: Para formar activistas e dirigentes dos movimentos sociais e ONGs e cientistas sociais, intelectuais e artistas dedicados à transformação social. Disponível em:

$<$ http://www.universidadepopular.org/media/artigos/Proposta_para discussao.pdf $>$. Acesso em março de 2014. Publicado em 2003. 